\title{
Developing an Environmental Performance Index (EPI): a focus on impacts of information and communication technology use
}

\author{
CMBOHWA ${ }^{1}$ AND J AGWA-EJON ${ }^{2}$
}

\begin{abstract}
There is a growing need for environmental performance measures that can be used by all stakeholders like surrounding communities, customers, suppliers and shareholders to gauge the environmental performance of organizations. The environmental performance measures that are used worldwide are normally not suitable for benchmarking organizations. This paper develops an environmental performance index using indicator and weight matrices of the full life cycle phases of an organization's energy use for environmental management system activities. This work is transdisciplinary in nature and applies mathematical matrices and environmental productivity approaches, and borrows from the development of quality indices to consider a variety of impacts that cut across various phases of a product life cycle and different functions within an organization. The focus is on information and communication technology use in these systems. The model is applied to the Japanese automotive industry and the findings show that it is feasible and effective for comparing the environmental performance of companies in the same sector using the same weight matrices and indicators agreed to. The work informs decision making on the development of environmental performance measures that have worldwide applications, across many disciplines, in situations where suitable data are recorded. It also contributes to efforts on economic and social sustainability. Research efforts in similar areas in Southern Africa can benefit from the development and improvement of the proposed methodology.
\end{abstract}

Keywords: Environmental performance index, indicator and weight matrices, benchmarking

Disciplines: Information and Communications Technology Studies (ICT), Environmental Studies, Economics, Sustainability Studies.

\section{Introduction}

International certification standards have been developed for environmental management systems. These are certified for set requirements as International Standards Organization (ISO) 14001 (ISO 14001, 2004). These systems do not specify any environmental performance measures. Empirical work has been done which suggests that firms with high environmental performance tend to be profitable (King and Lenox, 2001). However, the nature of this relationship is still unknown and is a subject of further inquiry. More important

1. Dr C Mbohwa is the corresponding author. He is attached to the Department of Quality and Operations Management, University of Johannesburg, Auckland Park Bunting Road Campus, P.O. Box 524, Auckland Park 2006, Johannesburg, South Africa. E-mail address: cmbohwa@uj.ac.za

2. Department of Quality and Operations Management, University of Johannesburg, Auckland Park Bunting Road Campus, P.O. Box 524, Auckland Park 2006, Johannesburg, South Africa. E-mail address: jagwa-ejon@uj.ac.za . 
still, the methods that can be used to measure environmental performance are still a subject of debate (Kuhre, 1998). The demands on companies to measure, document and disclose information about environmental performance are becoming more insistent due to pressures from employees, neighbours, the general public, environmental groups and regulatory agencies, making it become as important as the financial results (Tyteca et al., 2002).

While it is important for organizations to improve environmental management and performance, industries also seek economic efficiency and profitability. They would never adopt any environmental measures that violate this. The aim should therefore be to build a sustainable socio-economic system that ensures economic development while minimizing environmental burdens. The effectiveness of an environmental management system and the level to which it will satisfy the affected society and other stakeholders will require that organizations go beyond implementing systems according to ISO 14001 requirements to the measurement of real environmental performance using universally accepted methods. The overarching objective of an organization should be the improvement of both internal and external transparency about effects on the environment and responses to mitigate them. It should be able to measure the environmental impacts of its activities in ways acceptable to the stakeholders (Pun et al., 2003). Environmental impact assessment (EIA) aims to identify, measure and evaluate the environmental aspects of activities, products and services that can have environmental effects like resource depletion, land use, waste and emissions to the atmosphere and effluents to water. There is a direct relationship between EIA and ISO 14000 series and the tools and systems that link them (Pun et al., 2003). The tools include life cycle assessment (LCA), environmental auditing, environmental performance evaluation and environmental labelling.

This paper develops an index using a transdisciplinary approach. Transdisciplinary research aims to get researchers from different fields to collaborate, so as to achieve an integrated view of a subject that goes beyond the viewpoints offered by any particular discipline. Similarly, different methodologies from different disciplines are integrated to address a problem. One of the ways of conducting transdisciplinary research is to integrate the use of the quantitative and qualitative sciences in a research effort, which is done in this case. Research of this nature offers opportunities for methods that can solve problems more effectively and enables attempts of previously avoided problems. Knowledge packaged in particular disciplines is repackaged to make it useful and meaningful in solving a particular problem (Pohl, 2005).

The developed index measures environmental impacts of an organization using energy indicator and indicator weight matrices within an LCA framework and focusing on applications in the Japanese automotive industry. It develops matrix mathematical formulations, which are applied to the LCA methodology used in environmental science, engineering and management in order to create an index which can be used for assessing business, organization and industrial environmental performance, with possible extensions to the development of other sustainability indices. It focuses on environmental performance assessment by using an environmental performance index (EPI) to represent the impacts of the use of information and communication technology (ICT) in an environmental management system (EMS). A framework is developed for the determination of the EPI of ICT usage for any given organization. In this case, the index is defined as a number between 0 and 100 that measures the environmental performance of an organization, related to its use of ICT in a typical ISO 14001 certified environmental management system. It measures the 
level to which the use of ICT in the system contributes to improved or to more adverse environmental performance, depending on the particular and unique situation of the organization. A generic framework is proposed, which can be slightly modified for specific applications other than ICT use and can be modified if necessary and applied to specific organizations. Many companies can use this main framework in its normal state for general environmental performance measurement.

The next section reviews environmental performance literature. This is followed by the methodology and model development of the EPI. The model is applied to all nine Japanese automotive manufacturers without identifying them. The evaluated index for each company shows that some form of benchmarking based on environmental performance is possible. This is followed by a discussion and it is concluded that data collection would need to be improved if the full potential of using this methodology is to be realized.

\section{Review of environmental performance measurement}

Developing a single indicator for an organization involves measures that are from different fields. This problem is therefore complex and multifaceted and requires complex solutions which necessitate transdisciplinary approaches. This is in line with recent findings that useful knowledge generation for the benefit of society is increasingly demanding transdisciplinary approaches to problem solving and this signals a bright future for transdisciplinary research (Wickson et al., 2006). The main characteristics of transdisciplinary research are problem focus, evolving methodology and collaboration, making it the natural choice for such problems (Wickson et al., 2006). Transdisciplinary research is also a useful means of bridging science and policy and can go beyond informing public agencies, the private sector, or civil society of the results of research. It can be used to reorganize knowledge according to the interest of the audience and/or can initiate a co-production of knowledge during which the different policy cultures interact (Pohl, 2007). On the other hand, the terms 'sustainable development' and 'transdisciplinarity' are closely related in the discipline of ecological economics. This is because sustainable development research is issue oriented and reflects the diversity, complexity and dynamics of the processes involved as well as their variability between specific problem situations. The different disciplines can be integrated to attend to environmental issues or problem fields using inputs and perspectives from societal practices (Hadorn et al., 2006). This paper reflects that one aspect of sustainability, environmental impacts, are measured using transdisciplinary approaches.

An index has been developed that simultaneously accounts for resources used, good outputs produced and pollutants or undesirable outputs emitted computed using data envelopment analysis techniques. The best performance gives the highest ratio of good to bad outputs. The index measures the degree to which a firm, plant, industry or country has succeeded in producing good output while simultaneously accounting for reductions in bad outputs. It measures the ratio of a quantity index of good output to a quantity index of bad output and can be regarded as an environmental productivity index (Färe et al., 2004).

Environmental performance evaluation involves the use of indicators to quantify and qualify the effects of an organization's activities on the environment. The need for harmonization and standardization of the performance indicators has resulted in the formation of a variety of 
initiatives, like the Measuring Environmental Performance of Industry (MEPI) project (Tyteca et al, 2002), the Global Reporting Initiative (White, 1999; Mullins, 2000), the ISO 14031 standard (ISO 14031, 1999), Dow Jones Sustainability Group Index (DJSGI) (Knoepfel, 2001), which is used for investment screening purposes, and the eco-efficiency initiative led by the World Business Council for Sustainable Development (Verfaillie and Bidwell, 2000). An environmental indicator is concerned with measuring and tracking a firm's output to the physical environment. The derivation of critical environmental indicators is an important aspect in performance evaluation. In general a Plan-Do-Check-Act business process improvement model is used in environmental performance evaluation (ISO 14031, 1999).

\subsection{Developing performance indicators}

Environmental aspect indicators are used because of the unavailability of environmental impact data, which indicate or identify changes in the environmental quality of the system, and because of the complexities of attributing an organization's contribution to a complex and adaptive ecosystem such as the earth's environment. An environmental aspect is defined as an element of an organization's activities, products or services that can interact with the environment. Usually the term 'impact' describes changes in the environment and related socio-economic implications (Olsthoorn et al., 2001). However, most systems just end up measuring environmental aspects and these are then considered as environmental indicators. Using aspect indicators is also not easy due to lack of data in most organizations. There is thus a need to improve data collection so that recorded and published data track relevant aspects for sustainability as opposed to simple statistics of normally available data which are obtained using the old, often uninformative traditional data collection systems. The data can be presented as absolute or relative indicators to provide total performance and performance per production output. The types of indicators are as follows (Jasch, 2000):

- Absolute indicators like tons of raw materials, emissions or wastes

○ Relative indicators, for example energy use per square metre, emissions/US\$100,000 net sales

- Indexed indicators expressed as a percentage of a total or percentage change from last year

- Aggregated depictions of indicators of the same unit summed over a number of production steps or throughout a product's life cycle

○ Weighted evaluations depicting figures of varying importance using conversion factors

The principles for the derivation of environmental indicators laid down in ISO 14031 (1999) are:

- Comparability: Indicators must be comparable and reflect changes in environmental performance

- Target-oriented: Indicators must be chosen that can act towards goals within the capability of the organization

- Balanced: They must reflect environmental performance in a concise manner, displaying problems and benefits appropriately

- Continuity: They must be derived using the same criteria relative to each other through corresponding time series and units 
- Frequency: Indicators must be derived at an appropriate frequency so that timely intervention can be taken

- Comprehensibility: They must be understandable for users and correspond to user information needs

\subsection{Role of environmental indicators and benchmarking}

According to a number of authors (Olsthoorn et al., 2001; Jasch, 2000; Yim and Lee, 2002), the objectives of environmental benchmarking and the role of indicators are as shown in Table 1.

Table 1: Role of environmental performance indicators and benchmarking

\begin{tabular}{|l|l|}
\hline & Role of environmental performance indicator/benchmarking \\
\hline 1 & $\begin{array}{l}\text { Improve organization's efficiency, hence better environmental performance, by constant comparison with } \\
\text { previous indicators and with competitors (benchmarking) }\end{array}$ \\
\hline 2 & Create customer awareness of a product's environmental performance and defend market positions \\
\hline 3 & Satisfy green customers through design for the environment \\
\hline 4 & $\begin{array}{l}\text { Improve profitability through better resource efficiency and highlighting of optimization potentials particularly } \\
\text { in cost reduction }\end{array}$ \\
\hline 5 & $\begin{array}{l}\text { Enable continuous monitoring and improvements in environmental performance and enable regulatory and } \\
\text { permit compliance }\end{array}$ \\
\hline 6 & $\begin{array}{l}\text { Promote better understanding of environmental performance by stakeholders through better and focused } \\
\text { communication particularly in environmental reports }\end{array}$ \\
\hline 7 & $\begin{array}{l}\text { Enable commitment to specific goals through qualitative and quantitative monitoring, particularly at top } \\
\text { management level. Base for deriving targets, objectives and goals for back-casting }\end{array}$ \\
\hline 8 & Identify the most harmful emissions and wastes \\
\hline 9 & $\begin{array}{l}\text { Make it easy to create a database that can be used for developing and implementing environmental policies at } \\
\text { various levels including government level }\end{array}$ \\
\hline 10 & Provide a feedback instrument for the information and motivation of the workforce \\
\hline 11 & Provide technical support for EU-EMAS regulation and ISO 14001 \\
\hline
\end{tabular}

Sources: (Olsthoorn et al., 2001; Jasch, 2000; Yim and Lee, 2002)

\subsection{Efforts in environmental performance evaluation}

There have been many efforts to evaluate environmental performance using indicators. Recent efforts on environmental indicators are (ISO 14031, 1999; ISO 14032, 1999; White, 1999; Mullins, 2000; Jasch, 2000; Verfaillie and Bidwell, 2000; King and Lenox, 2001; Knoepfel, 2001; Olsthoorn et al., 2001; Yim and Lee, 2002; Tyteca et al., 2002):

- Association of Chartered and Certified Accountants (ACCA) Report on Environment-Related Performance Measurement

- Global Reporting Initiative (GRI)

- EU Eco-Management and Audit Scheme (EMAS)

- National Round Table on the Environment and the Economy (NRTEE)

○ World Business Council on Sustainable Development (WBCSD) Report - Ecoefficiency Metrics

○ World Resources Institute (WRI) Report

- EEA Working Paper on Eco-efficiency Indicators

- ISO 14031- Environmental Performance Evaluation 
- Guide to Corporate Environmental Indicators by the German Federal Environmental Agency

These efforts emphasize different multidisciplinary approaches to environmental performance measurements that can be applied in financial accounting, environmental accounting, environmental management, global measuring and business reporting, and in demonstrating corporate social responsibility. While EMAS, ISO, WBCSD and German Federal Environmental Agency initiatives are aimed more at internally oriented performance management, others like WRI, NRTEE, ACCA and GRI are more focused on external performance measurement. There is little standardization of the indicators and benchmarking is impossible. There is therefore a need for more standardization, measurement of ecoefficiency and sustainability, life cycle focus and benchmarking indexing. Standardization refers to efforts to increase data comparability between years, sites, functional units, products, resource users and organizations. This can be done through normalization, which is the transformation of data into compatible and comparable forms. The data is then aggregated, that is, transformed to give summary indicators giving an overview of total resource use, emissions and waste. Potency factors like ozone depletion potential and global warming potential are used for such aggregation.

\subsection{Types and proper usage of indicators}

The environmental performance indicators are divided into operational performance indicators, management performance indicators and environmental condition indicators, and examples are as shown in Table 2 (Putnam, 2002).

Table 2: Classification of typical environmental performance indicators

\begin{tabular}{|c|c|c|}
\hline Operational performance indicator & Management performance indicator & Environmental condition indicator \\
\hline $\begin{array}{l}\text { Raw material use/unit product } \\
\mathrm{kg} / \mathrm{unit}\end{array}$ & Environmental costs/budget per year & Contaminant in air $\mu \mathrm{g} / \mathrm{m}^{3}$ \\
\hline Annual use per unit $\mathrm{MJ} /$ product & \% environmental targets achieved/yr & Photochemical smog frequency/year \\
\hline Energy conserved $(\mathrm{MJ})$ & No. or $\%$ of employees trained/year & Water contaminants $\mathrm{mg} / \mathrm{L}$ \\
\hline No. of emergencies or shutdowns & No. of audit findings per year & Change in groundwater level $(\mathrm{m})$ \\
\hline Hours/year preventive maintenance & No. of audit findings addressed/year & No. of coliform bacterial/litre water \\
\hline Average fuel litres $/ \mathrm{km}$ of vehicles & Time/person-hours for corrections/yr & Soil contamination $\mathrm{mg} / \mathrm{kg}$ \\
\hline$\%$ of product content recycled & No. of environmental incidents/year & Land area rehabilitated (ha/per year) \\
\hline Hazardous waste $\mathrm{kg} / \mathrm{unit}$ made & Person-hours attending to incidents & $\begin{array}{l}\text { Contaminant in tissue of specific } \\
\text { local species }(\mu \mathrm{g} / \mathrm{kg})\end{array}$ \\
\hline Specific emission-kg/ $/ \mathrm{CO}_{2} /$ year & Number of complaints received/year & Specific species population No. $/ \mathrm{m}^{2}$ \\
\hline Noise at specific receptor $(\mathrm{dB})$ & No. of fines/violations per year & Increase in algae blooms (\%) \\
\hline $\begin{array}{l}\text { Wastewater discharged/unit } \\
\text { product }\end{array}$ & Suppliers consulted about EMS/yr & Asthma admissions in smog season \\
\hline $\begin{array}{lrr}\begin{array}{l}\text { Hazardous } \\
\text { through } \\
(\text { kg/year })\end{array} & \begin{array}{r}\text { waste } \\
\text { pollution }\end{array} & \begin{array}{l}\text { eliminated } \\
\text { prevention }\end{array} \\
\end{array}$ & $\begin{array}{l}\text { Cost of pollution prevention projects } \\
\text { per given year }\end{array}$ & $\begin{array}{l}\text { Number of fish deaths in a specific } \\
\text { watercourse }\end{array}$ \\
\hline $\begin{array}{l}\text { Days per year pollution limits } \\
\text { exceeded }\end{array}$ & $\begin{array}{l}\text { Management levels with specific } \\
\text { environmental responsibilities }\end{array}$ & $\begin{array}{l}\text { Employee blood lead levels }(\mu \mathrm{g} / 100 \\
\mathrm{m} \ell)\end{array}$ \\
\hline
\end{tabular}

Adapted from Putnam (2002)

Some indicators, like those using turnover, can be effective for the entire group, while production quantity is more suitable for a plant. Indicators can be given for specific products. 
Examples of indicators that can be used are amount of greenhouse gases emitted per unit turnover and amount of energy consumed per unit ton produced. The other types of environmental indicators measure the product or service value per unit environmental burden, which is a measure of eco-efficiency. This shows the improvement of economic value relative to environmental improvements. The indicators are also presented together with absolute values to ensure that there is no increase in total burden. Common core indicators like total amount of material input, energy consumption, greenhouse gases emitted, volume drained and waste produced need to be measured. Examples of eco-efficiency indicators are turnover per unit energy consumption, product function (e.g. fuel cost, distance covered) per unit energy consumption and products or services per unit input in tons. These are aimed at specific targets.

\subsection{Environmental performance models review}

An overview of the development of environmental performance evaluation models and typologies has been done to analyze their characteristics, strengths and weaknesses (Kolk and Mauser, 2002). These have consisted of stage or phase models describing the increasing integration over time of environmental factors and concerns into the business policy and strategy on one hand, and continuum models on the other. Simultaneously, typologies that merely characterize a company's position without assuming growing responsiveness over time have also evolved (Kolk and Mauser, 2002). A continuum in this case is regarded as a linear classification scheme that identifies a development in time, while a typology consists of conceptually derived interrelated sets of ideal types of models. Fifty models have been analyzed to identify the current status and the contribution that these models and performance instruments can make (Kolk and Mauser, 2002). However, comprehensive performance assessments are still unavailable even though the tenets of such systems can be delineated. Furthermore, the models cannot be applied easily to the actual behaviour of organizations. This poor fit with reality suggests that there is room for more specialized models that can suit particular aspects that are being modelled, like ICT applications; hence this effort to develop an EPI.

The index mentioned previously that measures the ratio of a quantity index of good output to a quantity index of bad output and that can be regarded as an environmental productivity index (Färe et al., 2004) is different from the index that is being developed here, which combines the bad outputs and good outputs. The best output has a score closer to 10 and the worst output has a score closer to 0 . Performance-based environmental index weights have also been developed. These measure environmental performance and provide the marginal performance for each metric by using a metric weighting scheme that incorporates each metric's marginal contribution to performance, at each site (Bellenger and Herlihy, 2010). A weighted version of the original index is obtained and this provides a similar measure of overall performance while also adding new information on the relative importance of each of the index metrics. The index can be used for benchmarking (Bellenger and Herlihy, 2010). Data from the toxic release inventory of electric power plants has also been used to construct an EPI. This index simplifies to the ratio of good to bad output for multiple bad outputs (Färe et al., 2010). 
In general ecological literature concentrates more on index metric choice and scoring. On the other hand economics literature tends to focus more on aggregation into a single index where possible. The former looks at the environmental attributes to include and the latter explores the appropriate methods to combine the separate chosen attributes into one composite measure of environmental performance (Bellenger and Herlihy, 2010). Implementation of models which focus on environmental management rather than environmental performance indicators is very difficult. This is because it is difficult to be consistent in setting management performance indicators. This adds to the argument that performance evaluation models are better tools for operational environmental aspects. The challenge would still be what, where and how to measure. Lessons can be learnt from the creation of indices in other fields. A quality competitiveness index for benchmarking has been developed (Kumar et al., 1999) and the measures used are analogous to those that are used for the development of the EPI in this paper.

\section{Methodology and model for the environmental performance index}

This section starts off with a description of the modelling framework for the EPI. While a general consideration of general environmental impacts is done, the focus is on the environmental impacts of ICT use in an EMS within the Japanese automotive industry. The developed model can be applied to all types of impacts and aspects. However, doing so here would make the analysis less thorough, hence the mentioned focus. The development of the indicators follows the approach shown in Figure 1.

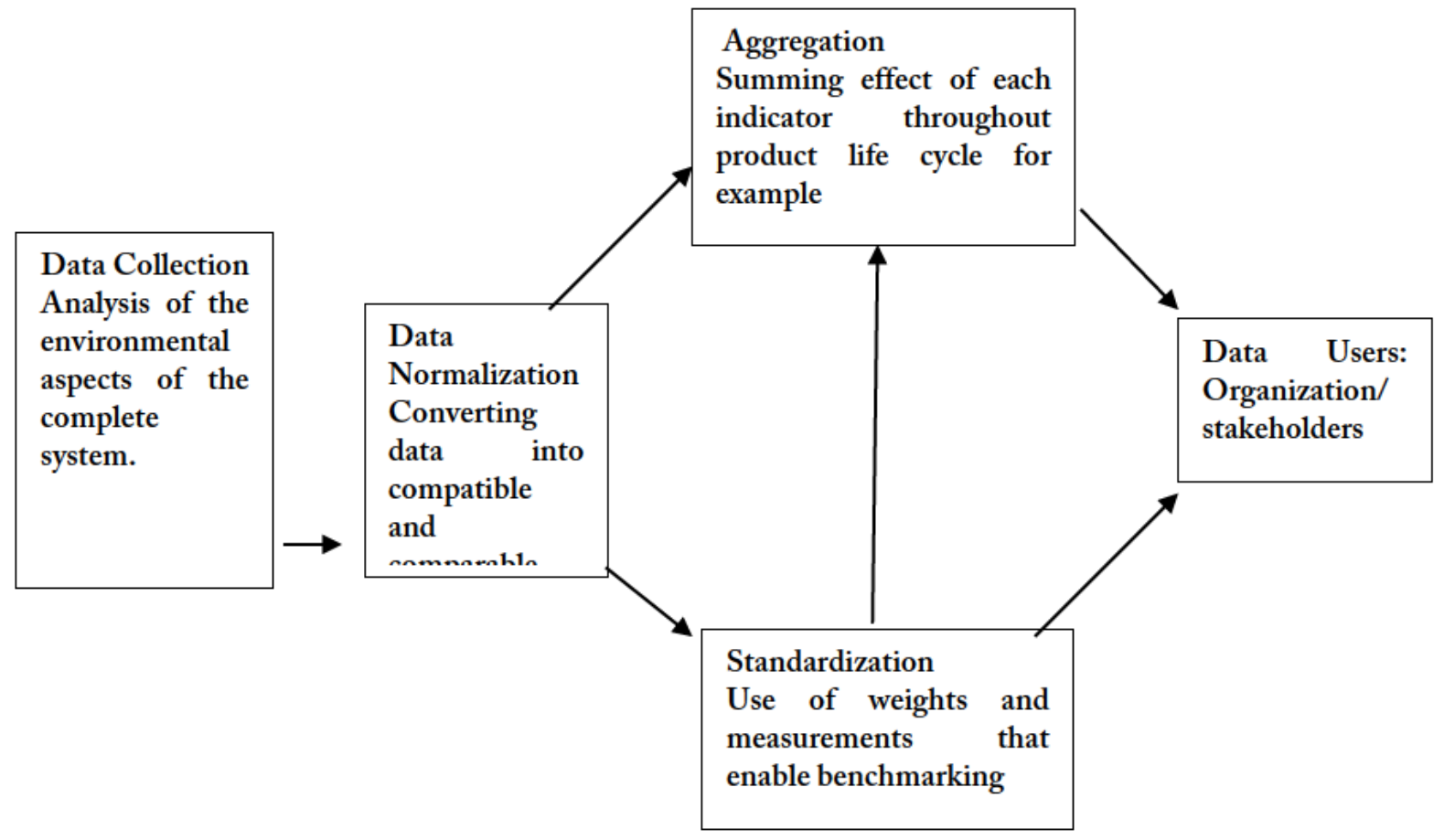

Figure 1: Methodology for developing environmental performance indicators

Data collection is a very demanding exercise. However, studies on specific parts of the system being analyzed can accumulate a lot of data and indicators. These have to be formalized in companies within one sector so that data become readily available for computing the EPI 
through data normalization and following the steps shown in Figure 1. Data were collected through document research using the documents from the Japanese automotive industry. Interviews and observations during visits to the automotive manufacturers yielded more information. The environmental management and sustainability reports produced by the car manufacturers in most of their subsidiaries as well as at corporate level were used to get critical data on ICT use and related environmental impacts. The data were converted to comparable ratios reflected in the mathematical model later. Aggregation and standardization of the data was done as necessary. Final data sets were collected in a form that could be used for evaluating the EPI. The development of the EPI of ICT use in an EMS specifically followed the phases illustrated in Figure 2.

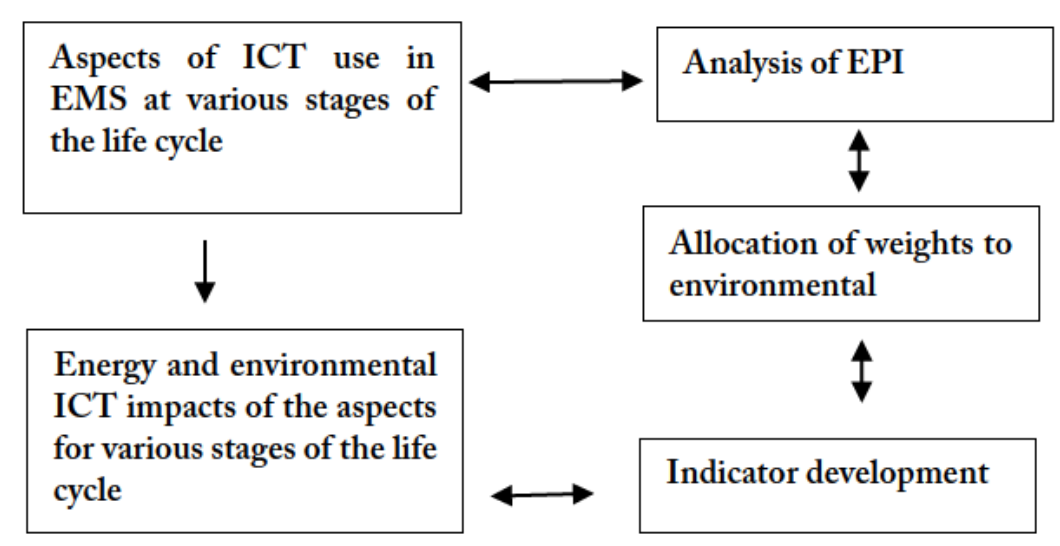

Figure 2: Methodology for creating the EPI

Data and information of ICT use at different stages of the life cycle of the production of a vehicle were collected, for example use of ICT in the design and development phase in areas such as computer-aided design, the use of numerical control in the pressing and fabrication sections, the use of ICT in the marketing and sales function, the use of ICT in the use phase of the vehicle and finally in the vehicle disposal phase. Energy and environmental impacts were tracked to assist in indicator development, allocation of weights based on subjective hierarchy as decided by the stakeholders and the analysis of the index.

The index developed could be very useful in indicating the position of a company. An organization can then benchmark its own performance, not only against that of other companies in the same sector, but against other organizations in other sectors as long as similar system boundaries are used. That way it will be motivated to find ways to improve its own operations in that area. Since the measure depends on internal factors and processes, benchmarking them against other organizations enables comparison and stimulates the need to learn from other organizations. Any weaknesses identified in the internal systems can be corrected, resulting in improved environmental performance. The index provides the level at which the company is pegged in terms of the environmental performance of its ICT usage in the EMS and simultaneously exposes many areas of weakness when compared to competitors and other organizations. Its use helps organizations to consider sustainability as a holistic strategy, particularly when used together with other indices beyond the application of ICT in $T D$, 7(1), July 2010, pp. 73-92. 
environmental management. The use can be extended to contribute to the field of organizational development and benchmarking on the basis of quantitative analysis, in addition to the traditional qualitative assessments.

Using this method, an organization with a very high score, between 0 and 100 , is deemed to be an excellent environmental performer, while one with a low score is the opposite. In developing the index, environmental management performance indicators and environmental condition indicators were not considered. This is because management indicators do not directly measure the aspects that influence the environment, while conditional indicators only measure the after-effect, and are therefore not useful for benchmarking the performance of organizations in the same sector. Operational performance indicators were therefore used and these were assessed using matrices or arrays and LCA in a MATLAB environment. An LCA framework is proposed for product manufacturing companies, which covers the entire product cycle from procurement, design through to manufacturing, use, maintenance and final disposal as shown in Figure 3. This shows the methodology used in this study, dividing the phases of the vehicle life into the upstream activities, the inputs and outputs of the operational phase of the vehicle and the downstream phase, which is mainly concerned with how the vehicle is disposed of. The ICT hardware poses disposal challenges since it contains hazardous substances.

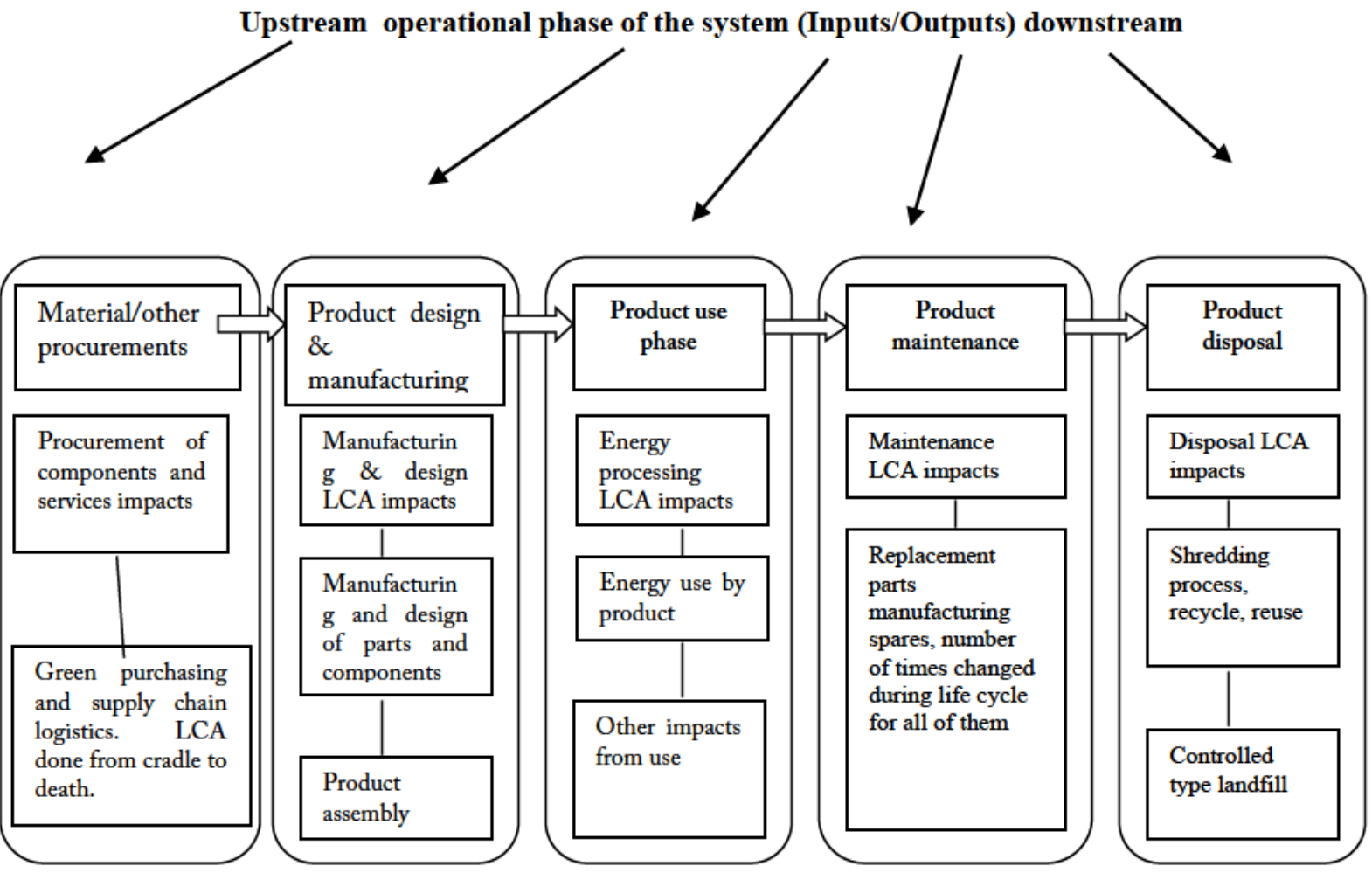

Figure 3: Proposed life cycle assessment framework

The external procurement of parts, components, materials and services represents the upstream supplier side of the logistics supply chain. The model assumes that procurement is the only upstream activity. The product design and manufacturing is the operational phase of a car manufacturer. An analysis of the inputs and outputs of these activities provides data on its burdens to the environment attributable to the company's internal activities. This includes 
the company's EMSs, development and design activities, its internal material procurement, production and logistics and internal recycling services. The use and maintenance of the vehicles and the disposal of the vehicles after their useful life phases are considered as being downstream activities. The main phases used in the LCA formulation are therefore upstream, internal inputs, internal outputs and the downstream activities. The operational environmental performance indicators were the only ones considered in this case and they are discussed in the following sections with a focus on the Japanese automotive industry applications. While the LCA method of EIA is applied, the nature of the data collected naturally forms a matrix that is manipulated to give a single number, which is taken as the index.

\subsection{Operational performance indicators (OPIs) of inputs in upstream sectors}

Green purchasing or preferential purchase of environment-conscious products and services has a positive effect on the environment. For example, in Japan, environment-conscious products and services are defined in clause 1 of article 2 of the aw regarding promotion and procurement of environmental articles by country etc. These include use of recycled resources, recycled components, reduction of pollutants, low energy consumption, reuse and use of vehicles that emit low levels of exhaust gases (Ministry of the Environment, Japan, 2009). Prior assessment of materials used in vehicle production can be done to determine environmental impacts upstream (Toyota, 2008). The analysis of these upstream aspects is the first step and involves the identification of the various environmental aspects in the organization concerned. These have to be identified exhaustively. Any operational procedures, factors and practices that can have a negative or positive effect on the environment should be listed and these can be represented as $A_{i j}$, for $i=1 \ldots I$ and $j=1 \ldots J$, where $i$ is the index of the environmental aspect and $j$ is the index of the sub-factor of the aspect for the upstream sector. Typical environmental aspects and their sub-factors related to ICT use in an EMS in the production phase of the report are shown in Table 3.

Table 3: Typical environmental aspects of ICT and the related sub-factors for the operational phase

\begin{tabular}{|c|c|}
\hline Factor or aspect & Sub-factors of the environmental aspect \\
\hline Paper use & $\begin{array}{l}\text { Weight of paper per annual environmental report, weight of EMS and communication } \\
\text { documentation, operational records, document control procedures and EMS records }\end{array}$ \\
\hline $\begin{array}{l}\text { Health aspects } \\
\text { hazards }\end{array}$ & $\begin{array}{l}\text { ICT-generated hazardous chemicals releases/mobile communication capacity per sales volume. } \\
\text { Classified by type of chemical }\end{array}$ \\
\hline $\begin{array}{l}\text { Energy } \\
\text { consumption }\end{array}$ & $\begin{array}{l}\text { ICT energy use/unit output, ICT contribution to energy efficiency of products/unit } \\
\text { measurement, emission of pollutants/MJ consumed, renewable energy used/total energy used, } \\
\text { improved energy efficiency/unit output due to ICT-based energy management system, } \\
\text { information technology hardware and software electricity consumption and telecommunications } \\
\text { equipment consumption of power/shipment value }\end{array}$ \\
\hline Logistics & $\begin{array}{l}\text { ICT-induced energy savings/net sales, other environmental impact reductions/net sales; consider } \\
\text { aspects like intelligent transportation systems, electronic logistics, telecommuting, e-mails, } \\
\text { electronic auditing, telephone and videoconferences, distance education and training and travel } \\
\text { replacement through e-commerce indicators. Consider energy use, emissions and other } \\
\text { environmental aspects. ICT load factor, ton-km/net sales, route planning, digital maps, B2B and } \\
\text { B2C systems integration, travel reduction/employee. Enabling JIT }\end{array}$ \\
\hline $\begin{array}{l}\text { Material use and } \\
\text { waste reduction }\end{array}$ & $\begin{array}{l}\text { ICT recycling \%, ICT-enabled green purchasing and Internet auctions } \% \text {, ICT-induced } \mathrm{CO}_{2} \\
\text { reductions from recycling, ICT-induced waste reduction as } \% \text { of total inputs, ICT-based } \\
\text { improvement in material conversion efficiency, total ICT equipment/net sales, ICT assistance to } \\
\text { optimize factors of safety as } \% \text { material used reduction. Resource efficiency - light weighting, fuel } \\
\text { consumption/net sales, material substitution, packaging indicators }\end{array}$ \\
\hline
\end{tabular}




\begin{tabular}{|c|c|}
\hline $\begin{array}{l}\text { Dematerialization/ } \\
\text { immaterialization }\end{array}$ & $\begin{array}{l}\text { Indicators for e-mails, electronic documents, electronic/traditional training and education, digital } \\
\text { photography, video downloading, paper use volume, immaterial products development, manual, } \\
\text { bills, invoices, receipts, LAN, groupware, web, file transfer, services as } \% \text { of net sales }\end{array}$ \\
\hline $\begin{array}{l}\text { Electronic media } \\
\text { video and } \\
\text { teleconferencing }\end{array}$ & $\begin{array}{l}\text { Indicators for energy use reduction, } \mathrm{CO}_{2} \text { emission reduction, waste from related hardware and } \\
\text { software, number of people trained by system, transport reduction, reduced accommodation } \\
\text { needs, impacts of electronic auditing; all measured per set net sales, training and education } \\
\text { indictors all/net sales }\end{array}$ \\
\hline ICT green design & $\begin{array}{l}\text { Design simulation impacts, prototype impacts, ICT controls of motors, LCA design effect, } \\
\text { reduction/elimination of packaging, recycle material use, specifications for green procurement, } \\
\text { ICT take-back systems, design for reuse and disposability all per unit of net sales }\end{array}$ \\
\hline Process control & $\begin{array}{l}\text { Microprocessor effects for better engine performance or less emissions, litres } / \mathrm{km}, \mathrm{CO}_{2}, \mathrm{CO}, \mathrm{SO}_{2} \\
\text { and } \mathrm{NO}_{\mathrm{x}} \text { released, energy from brakes, transmission optimization, reduced energy consumption, } \\
\text { process management and monitoring, process optimization and process design benefits per net } \\
\text { sales (Jantzen, 2001) }\end{array}$ \\
\hline Buildings & $\begin{array}{l}\text { Energy intensity } / \mathrm{m}^{2} \text { for lighting, heating, powering ICT equipment, impact of smart windows, } \\
\text { intelligent controls, elevator optimization systems, intelligent houses, ozone-friendly refrigerants } \\
\text { for air conditioning and office space reduction due to ICT use } \mathrm{m}^{2} / \mathrm{net} \text { sales, land area saved, extra } \\
\text { space and land requirements for servers, computers, ICT equipment } / \text { net sales }\end{array}$ \\
\hline Rebound effect & $\begin{array}{l}\% \text { energy increase from rebound effect, resources, material, paper, ICT equipment, increase in } \\
\text { person- } \mathrm{km} \text { and ton-km, air transportation use impacts all/net sales }\end{array}$ \\
\hline
\end{tabular}

This spans a range of activities and disciplines including paper use impacts, chemical and pollution effects on health, usage of renewable and fossil energy, performance of logistics systems, material use and substitution, waste, electronic and process control systems and the rebound effect, which has to do with worsening environmental performance as a result of easy affordability and higher volume usage. All these aspects are attended to from the perspective of how ICT is applied in these disciplines.

Similar aspects and sub-aspects are applied to the inputs and outputs within an organization and to the downstream sector as well. $A_{\mathrm{ij}}$ is assigned a value score between 1 and 10, which indicates its importance in either increasing or reducing the potential environmental impacts of ICT in the organization. The environmental impact is simply any change to the environment, whether adverse or beneficial, wholly or partially resulting from an organization's activities, products or services. A very positive environmental impact or environmental benefit attracts a high score, while an extremely negative impact or environmental burden is allocated a very low score. Most models tend to use a negative score for negative impacts on the environmental burden. However, this is not feasible when developing an index reflected as a number between 0 and 100. On the other hand a rule of thumb can be developed that scores of 0 to 5 are reserved for negative impacts on the environment and scores of 6 to 10 for positive impacts. This enables easier modelling. This can be benchmarked against best practice. The real impact is not measured, however; the aspect is measured and a reduction of its concentration or volume is assumed to have a positive effect on the environment.

\subsection{OPIs of inputs within an organization}

The basic OPIs are given by the total input of materials and amount of sustainable use of materials into the EMS in tons. Current exploitation of large quantities of resources releases many substances harmful to the environment beyond its restorative ability. Drastic solutions such as resource conservation, reutilization, recycling and thermal cycling are therefore needed. The input material includes raw materials, products, parts, components, facilities, equipment and operational sites. The material is classified by chemical elements and compounds and material type, and can be measured by volume instead of weight, such as the 
case with wood. New investment, rebuilding and replacement of equipment and facilities are part of the inputs. These aspects are considered for ICT use in the EMS only, in this case. Substances used cyclically are not considered as part of the material input. Energy input is an important OPI. This can be classified into total energy consumed and renewable energy consumed by the EMS. Fossil fuels are a major contributor of carbon dioxide to the atmosphere, causing global warming. There is a need to improve energy consumption efficiency and to increase the usage of renewable energy to reduce this impact. A breakdown of how electricity or each fuel is used is to be given. Energy consumption by own transportation systems in traditional systems is included to allow for comparisons with the electronic system.

Water input OPIs are very important. The amount of water used or reused for the EMS, measured in cubic metres, is given. Excessive use of water has to be avoided and pumping of too much groundwater can cause land subsidence. Water conservation and recycling are the key. Recycled water is not included when the indicators are computed.

The second step involves the same procedure as in section 3.1 for inputs to the organization. The factors and sub-factors can be similar to those in the first step and Table 2 represents the relationships. The environmental factors of the inputs into the company are denoted by $\mathrm{B}_{\mathrm{kl}}$ for $\mathrm{k}=1 \ldots \mathrm{K}$ and for $1=1, \ldots \ldots . \mathrm{L}$, where $\mathrm{k}$ represents the environmental aspect of the EMS inputs within the company and 1 is the index of the sub-factor of the aspect. The sub-stages would have to be identified bearing in mind they are being assessed for ICT usage in this case and its impacts on the environment.

\subsection{OPI of outputs within an organization}

The main output OPI is based on emissions to the air. Greenhouse gas emissions related to the EMS are measured in tons or equivalent tons of carbon dioxide (Ministry of the Environment, Japan, 2009). In Japan, for example, carbon dioxide accounts for $88.9 \%$ of greenhouse gases emitted mainly from fossil fuels. In 1998, 1188 million tons of carbon dioxide were emitted in Japan, about 9.39 tons per capita. This is $5.6 \%$ more than in 1990 and represents a $3.2 \%$ per capita increase over the same period. Therefore $\mathrm{CO}_{2}$ and other greenhouse gas emissions are critical and any way of reducing them is a step in the right direction. There is therefore a need for good indicators of the emission of greenhouse gases to enable effective monitoring and inform decisionmaking. The other output indicators measure the amount of ozone depleting substances released by an organization due to the use of ICT in the EMS in tons. Amounts from discarded air conditioners, refrigerators and other products are included in the calculations. OPIs of emissions from EMSs to water and soil depend on the total amount of drainage to these systems. The drainage water needs to be recycled otherwise water pollution by chemical oxygen demand, phosphorus, nitrogen, heavy metals and toxic chemicals as well as by eutrophication of lakes, marshes and sea areas would occur. The amount of rainwater not recycled or reused is not considered as drainage.

The OPIs for waste generated should be monitored. Another indicator is the measurement of recyclable resources from EMSs that are thermally recycled. Some waste might be difficult to recycle due to technological and economic limitations. One way of using such waste is thermal recycle, methane formation through anaerobic fermentation and use in coke and blast 
furnaces. Cogeneration systems can be set up to maximize energy recovery. Measurements can be made of the ICT waste incinerated and of the final waste disposed (landfill etc.) in tons. Incineration processing is when waste is burnt without thermal recycle. Waste that is difficult to dispose of, such as radioactive and hazardous waste, is monitored and assessed separately. The analysis of environmental aspects of the outputs from an organization is the third step and similarly yields the variables $\mathrm{C}_{\mathrm{mn}}$ for $\mathrm{m}=1 \ldots \ldots \mathrm{M}$ for outputs from the organization and $n=1 \ldots \ldots . . N$, where $m$ denotes the environmental aspect and $n$ is the index of the sub-factor of the aspect.

\subsection{OPI of outputs in downstream sectors}

The characteristics of a product or service can indicate whether or not it promotes more environmental burdens or preservation. The use phase of the product or service and its disposal are often in the downstream of the company. The other indicators in the downstream of an organization are in transportation. The $\mathrm{CO}_{2}$ emissions from transportation are increasing in Japan. In 1998, transportation emissions were 21.1\% above those in 1990 and accounted for 21.7\% of all emissions (Ministry of the Environment, Japan, 2009). Transportation efficiencies can be achieved through higher capacity utilization, joint transportation and delivery, back-loading of vehicles and avoiding the rejection of goods, which would have to be transported back. Some of these systems require the use of ICT systems, and environmental management of the downstream activities lends itself to the use of ICT as well. In addition, more efficient vehicle engines can use ICT-based systems to reduce the environmental burdens. It is necessary to have another indicator that measures actual $\mathrm{CO}_{2}$ emissions from transportation in tons. A modal shift from vehicles and aeroplanes to rail and marine transportation systems is recommended whenever possible. It offers environmental benefits, when ICT systems are compared with traditional systems in environmental management. This analysis is the fourth step and the variable $\mathrm{D}_{\text {op }}$ for $\mathrm{o}=$ $1 \ldots . . \mathrm{O}$ and $\mathrm{p}=1 \ldots . . \mathrm{P}$ is used for the downstream aspects, where $\mathrm{o}$ denotes the environmental aspect and $\mathrm{p}$ the sub-factor of the aspect.

\subsection{Definition of the EPI}

There are four main aspects that are considered in developing the index, namely the upstream, internal input, internal output and the downstream environmental aspects, which have been described in the last sections. These cover the operational environmental performance of an organization within an LCA framework. It is noted that the performance indicators are in the form of matrices, rendering them amenable to matrix and array manipulation programming. The assignment of the values $A_{\mathrm{ij}}, \mathrm{B}_{\mathrm{kl}}, \mathrm{C}_{\mathrm{mn}}$ and $\mathrm{D}_{\mathrm{op}}$ are based on the method of assigning indicators as derived from the model of Jaggi and Freedman (1992). This is modified to reflect variables that measure the environmental impact of ICT use in an EMS. Every selected variable is first normalized. Dividing it by the level of output production does this:

$$
V=\frac{\text { Variable }}{\text { Output }}
$$

$V$ is the normalized environmental indicator. A minimum possible normalized value of the variable indicators $V \mathrm{~min}$ is identified. This can be the minimum within the company or 
sector for the given system. Where possible, the best practice variable is chosen. This is also normalized:

$$
V \min =\min (\text { Variable } / \text { Output })
$$

The contribution of that variable to the environmental impact is then given by:

$$
V \text { cont }=10 * V \min / V
$$

Vcont in this case represents the various values of $A_{i j}, B_{k l}, C_{m n}$ and $D_{o p}$ and is deliberately maintained between the values of 0 and 10. The indicators have to be manipulated in such a way that a higher value always indicates better environmental performance and a lower value a poor environmental performance.

The final step involves the assessment of functions within the company to identify the applications that are critical in influencing the impacts of ICT on the environment when applied in an EMS. To understand this matrix, algebra and relevant MATLAB aspects are presented. An array multiply (TIMES) of two matrices $\mathrm{X}$ and $\mathrm{Y}$ is given as $\mathrm{X}$. ${ }^{*} \mathrm{Y}$, which denotes an element by element multiplication in the MATLAB environment. This is provided that $\mathrm{X}$ and $\mathrm{Y}$ have the same dimensions or that at least one of them is a scalar. In formulating the index, an indicator matrix undergoes array multiplication with a weight matrix of its weights. It should be emphasized that this is not normal matrix multiplication, which would have resulted in a more complex formulation. Normal matrix addition is then applied to the products of the array multiplication. It is necessary to ensure that all the matrices have the same dimensions. Zeros are applied where the dimensions are different to bring them to the same dimensions.

The weights of the EMS environmental indicators are denoted by $w_{i j}, w_{k l}, w_{m n}$ and $w_{o p}$ and applied to respective indicators that share similar indices. They are used to signify the importance of the factor in causing environmental impacts. The allocation of these weights has to be done carefully, since they affect the final value of the index. Experts are needed in assigning them. Once the weights are assigned, comparative analysis between organizations becomes more objective. The formula below is when all the multiplication is array multiplication of each element of the indicator matrix with an equivalent element of the weight matrix. Summation is that of a normal matrix done until a single figure is obtained.

$$
E P I_{I C T}=\frac{10\left(\sum_{i=1}^{I} \sum_{j=1}^{J} w_{i j} A_{i j}+\sum_{k=1}^{K} \sum_{l=1}^{L} w_{k l} B_{k l}+\sum_{m=1}^{M} \sum_{n=1}^{N} w_{m n} C_{m n}+\sum_{o=1}^{O} \sum_{p=1}^{P} w_{o p} D_{o p}\right)}{\sum_{i=1}^{I} \sum_{j=1}^{J} A_{i j}+\sum_{k=1}^{K} \sum_{l=1}^{L} B_{k l}+\sum_{m=1}^{M} \sum_{n=1}^{N} C_{m n}+\sum_{o=1}^{O} \sum_{p=1}^{P} D_{o p}}
$$

The formula was applied to indicators estimated based on data gathered from the nine Japanese automotive manufacturing companies, which are referred to as A, B, C, D, E, F, G, $\mathrm{H}$ and $\mathrm{I}$ to maintain anonymity. Some of the indices were estimated from their annual environmental management reports. While the indicators were not accurately derived, the 
main idea was to test the feasibility of the formulation, rather than accurately benchmark the companies.

\section{Results and discussion}

Table 3 was used as a framework for the assessment. Paper use was classified under material use and waste reduction. When it was completely replaced, it was considered as immaterialization. In this case the indicator matrices were limited to a dimension of ten columns by five rows. The five most important sub-aspects were used in cases where more existed. If less existed, a value of 0 was used, nullifying the effect in both the numerator and denominator, even though the same weight matrices were used for the nine companies. The results of applying the EPI model to the Japanese vehicle manufacturing companies are shown in Table 4 . The names of the companies are replaced with letters for anonymity.

Table 4: Evaluation of the EPI for Japanese automotive manufacturers

\begin{tabular}{|l|l|l|l|l|l|l|l|l|l|}
\hline Company & $\mathrm{A}$ & $\mathrm{B}$ & $\mathrm{C}$ & $\mathrm{D}$ & $\mathrm{E}$ & $\mathrm{F}$ & $\mathrm{G}$ & $\mathrm{H}$ & $\mathrm{I}$ \\
\hline Numerator value & 71,028 & 58,435 & 83,126 & 68,364 & 75,846 & 62,695 & 56,039 & 78,293 & 65,348 \\
\hline $\begin{array}{l}\text { Denominator } \\
\text { value }\end{array}$ & 993 & 883 & 1,004 & 984 & 1,026 & 873 & 821 & 986 & 842 \\
\hline EPI & 72 & 66 & 83 & 69 & 74 & 72 & 68 & 79 & 78 \\
\hline
\end{tabular}

The results show that the model can be used to benchmark the environmental performance of the EMS in companies based on the criteria set. The EPI of ICT usage in the EMS, EPIICT, is a number between 0 and 100. This wide range makes it possible to detect small changes in the performance measure. A higher value reflects better environmental performance. The way this number is interpreted will have to be done carefully. It is intended to represent how the organization is doing in terms of the environmental performance of usage of IT in meeting environmental management objectives. The usefulness of the number will depend on the assessment of the factors, which can make this interpretation inaccurate. The inaccuracies can arise from a number of sources, including the following:

- The other dimensions of environmental performance may be confounded in the index. For example, paper use reduction due to ICT use can result in energy use reduction even though these are treated as separate environmental aspects. Similar issues can also be at play when transport optimization is considered separately from transport substitution issues. Thus the net effect of the environmental impact can be directly or indirectly influenced by a variety of factors that have related dimensions. These can also affect other areas like costs, even though for this purpose they are limited to environmental impacts only.

- Another source of inaccuracy can be the use of ICT factors that remotely affect the environment. The allocation of weights to signify the importance of a factor helps to reduce this error. The level of effect on the environment is given on the same scale and is either weakened or strengthened by the weighting given. Nevertheless some impacts will be overemphasized and others underemphasized. Furthermore, the allocation of weights could be subjective, resulting in different results when different people do the assessment. 
The EPI can be a reliable measure of the environmental performance of ICT usage in the EMS in organizations. It is noted that this can be extended to cover other indicators beyond EMS application and ICT use. However, the current model has been limited to ICT usage in the EMS to reduce its complexity and to demonstrate that the formulation can provide a very useful tool for gauging the environmental performance for particular applications. The environmental issues differ across industries; hence the EPI proposed can be a reliable measure when used within an industrial sector, making it useful for intra-industry comparison. Similar issues should be compared; the application here is therefore limited to ICT environmental performance in EMS.

The value of the index is determined by the factor quantities and factor weights that are used in the formula. Experts with a good understanding of the environmental factors and the related impacts must determine the weights. They would need to be tested through extensive empirical experimentation. This is the most difficult part, which would involve experiments in many industries using this methodology; hence the need to further refine the proposed framework. The values that reflect the degree of environmental impact must be chosen carefully.

The results in general reflected the environmental and sustainability awareness and practice in the different companies. Company $\mathrm{C}$ has produced annual environmental reports and sustainability reports since 1999. Its activities also included development of energy-efficient cars, hybrid vehicles and fuel cell cars. The top score obtained is justified. On the other hand, company B lagged behind in environmental awareness and reporting, with the first comprehensive corporate environmental effort being reflected in 2002. It was the last company to adopt improved EMSs and to report on its environmental performance. However, it is noted that more work needs to be done to fully validate the model developed.

\section{Conclusion}

This paper has made significant attempts to develop an index for environmental performances of individual organizations. Although the focus is only on ICT usage in this case, such indices can be extended to cover other organizational activities, such as transport and manufacturing, with possible application in Southern Africa and other countries worldwide. Given that environmental awareness is mounting all over the world, it can be expected that organizations will be subject to increasing pressure in future to reduce their carbon footprints. Additionally, although there are sophisticated calculation methods for greenhouse gas emissions for individual countries - the emission mitigation measures being subject to heated debate - it is unacceptable to assume that individual organizations are not bounded by such concerns. Thus, comparable performance measures need to be developed and this article has done that. This has been done using a transdisciplinary approach that sourced for ICT environmental impacts data across disciplines and across organizational functions. Data manipulation with matrices using MATLAB is normally a mathematics, operations research or engineering analysis methodology. This has been applied to environmental science methods within the developing field of LCA. Through weighting and analysis, this has been reduced to a number that tries to capture the overall environmental performance of an organization. 
A framework has been laid out that constitutes an important tool for companies that want to determine an EPI that can be used for benchmarking organizations in the same sector. The index that reflects their environmental performance when using ICT in an EMS has been developed. The formulation involved the use of an LCA methodology that generated aspects and sub-aspects that were manipulated in the form of mathematical matrices using MATLAB software. The developed index can be used to rank organizations in the same sector based on their environmental performance within the set system boundaries. The process of the identification of the environmental aspects or factors and the use of weights by an organization also creates useful intelligence on the strengths, weaknesses, opportunities and threats of an organization in terms of environmental and sustainability issues. This will assist in providing a foundation for long-term sustainability since it can be used as a tool for back-casting by designing the necessary data collection systems and methods so that all useful data are captured. Back-casting is thus a way of constructing a desirable future as opposed to forecasting, which is a way of predicting a likely future state of affairs.

The limitation of the use of the EPI is the fact that data on many variables that are considered are scarce. In this case estimates were made based on available data and annual environmental report results that depend on ICT use in the EMS. The interpretation of the results, which are synthesized using the model, should therefore be done with care. The need for a systematic collection of data on the most significant variables is identified. There is more value in collecting data on a regular basis on less but most significant variables as opposed to collection on general data that are not used at all. Attention must be drawn to supplement and standardize the information about the variables. This would provide a useful tool to improve environmental management and performance. As indicated earlier, immediate future research efforts can be applied to more comprehensive validation of the model. The most important contribution of this index and its methodology is that it presents data and results in such a format that they can be applied to company strategy development. It also overcomes the two main problems confronted when benchmarking between companies, namely the lack of consensus regarding what to compare on one hand, and varying system boundaries on the other. The method developed can be applied universally and can contribute to similar research work in the context of the Southern African situation. This can contribute to efforts in development studies, sustainability assessment and indexing and in the broader field of life cycle management in transport, mining, automotive production and other sectors, since all performance data can be reduced to a number using weights in the modelling process.

\section{References}

1. Bellenger M. J., and Herlihy A. T., 2010, "Performance-based environmental index weights: Are all metrics created equal?”, Ecological Economics 69 (2010) 1043-1050

2. Färe R., Grosskopf S., and Hernandez-Sancho F., 2004, "Environmental performance: An index number approach", Resource and Energy Economics 26 (2004) 343-352

3. Färe R., Grosskopf S., and Pasurka, Jr. C. A., 2010, “Toxic releases: An environmental performance index for coal-fired power plants", Energy Economics 32 (2010) 158165 
3. Hadorn G. H., Bradley D., Pohl C., Rist S., and Wiesmann U., 2006, "Implications of transdisciplinarity for sustainability research", Ecological Economics 60 (2006) 119128

4. ISO 14001, 2004, International Standard ISO 14001, Environmental management systems - Specifications with guidance for use, Technical Committee 207, Geneva: International Standards Organization

5. ISO 14031, 1999, International Standard ISO 14031: Environmental management Environmental performance evaluation, Technical Committee 207, Geneva: International Standards Organization

6. ISO 14032, 1999, ISO/TC207/SC4/JWG ISO/TR 14032: 1999 - Examples of environmental performance evaluation (EPE), Geneva: International Standards Organization

7. Jaggi B., and Freedman M., 1992, “An examination of the impact of pollution performance on economic and market performance: Pulp and paper firms", Journal of Business Finance and Accounting 19, 697-713

8. Jantzen J., 2001, Information technology and potential positive environmental effects thereof in

processing industries, Proceedings of Sustainability in the Information Society, $15^{\text {th }}$ International Symposium on Informatics for Environmental Protection, Zurich 10-12 October 2001, 99-106

9. Jasch C., 2000, "Environmental performance evaluations and indicators", Journal of Cleaner Production, 8 (2000) 79-88

10. King A. A., and Lenox M. J., 2001, "Does it really pay to be green? An empirical study of firm environmental and financial performance”, Journal of Industrial Ecology, 5 (1)

11. Knoepfel I., 2001, "Dow Jones Sustainability Group Index: A global benchmark for corporate sustainability," International Journal of Corporate Sustainability, Corporate Environmental Strategy, 8 (1) 6-15

12. Kolk A., and Mauser A., 2002, "The evolution of environmental management: From stage models to performance evaluation", Business Strategy and the Environment, 11, 4-31

13. Kuhre W. L., 1998, ISO 14031 - Environmental performance evaluation (EPE): Practical tools for conducting an environmental performance evaluation, Prentice Hall, Upper Saddle River, NJ

14. Kumar A., Motwani J., Douglas C., and Narayan D., 1999, “A quality competitiveness index for benchmarking”, Benchmarking: An International Journal, 6 (1) 12-21 
15. Ministry of the Environment, Japan, 2009, Environmental performance indicators for businesses for the year 2000, http://www.env.go.jp/en/ Last accessed on 12 December 2009

16. Mullins J. M., 2000, Public accountability: Disclosure in a competitive environment, prepared for the Environmental, Health and Safety Auditing Roundtable Newsletter. http://www.globalreporting.org Last accessed on 14 September 2010.

17. Olsthoorn X., Tyteca D., Wehrmeyer W., and Wagner M., 2001, "Environmental indicators for business: A review of the literature and standardization methods", Journal of Cleaner Production, 9 (2001) 453-463

18. Pohl C., 2005, “Transdisciplinary collaboration in environmental research”, Futures 37 (2005) 1159-1178

19. Pohl C., 2007, "From science to policy through transdisciplinary research", Environmental Science and Policy 11 (2008) 46-53

20. Pun K.-F., Hui I.-K., Lewis W. G., and Lau H. C. W., 2003, "A multiple-criteria environmental impact assessment for the plastic injection molding process: A methodology", Journal of Cleaner Production, 11 (2003) 41-49

21. Putnam D., 2002, ISO 14031: Environmental Performance Evaluation, Draft Submitted to the Confederation of Indian Industry Journal, September 2002.

22. Toyota, 2008, Toyota Motor Corporation: Environmental report 2001, August 2001, Toyota Motor Corporation Environmental Affairs Division, Tokyo

23. Tyteca D., Carlens J., Berkout F., Hertin J., Wehrmeyer W., and Wagner M., 2002, "Corporate environmental performance evaluation: Evidence from the MEPI Project”, Business Strategy and the Environment, 11, 1-13.

24. Verfaillie H. A., and Bidwell R., 2000, Measuring eco-efficiency - A guide to reporting company performance. World Business Council for Sustainable Development, Conches-Geneva

25. White A. L., 1999, "Sustainability and the accountable corporation: Society's rising expectations of business". Environment 41 (8) 30-43

26. Wickson F., Carew A. L., and Russell A. W., 2006, "Transdisciplinary research: Characteristics, quandaries and quality”, Futures 38 (2006) 1046-1059

27. Yim H., and Lee K., 2002, Environmental benchmarking methodology for the identification of key environmental aspects of a product, IEEE International Symposium on Electronics \& the Environment, 6-9 May 2002, San Francisco, CA, USA 